\title{
Morphology of inorganic-organic systems consisting of polyhedral oligomeric silsesquioxanes (POSS) and polyamide 6
}

\author{
Jenny Alongi, ${ }^{1}$ Orietta Monticelli, ${ }^{2}$ Saverio Russo, ${ }^{2 *}$ Jocelyne Galy, ${ }^{3}$ Jean-François \\ Gérard $^{3}$
}

${ }^{1}$ Dipartimento di Scienza dei Materiali e Ingegneria Chimica, Politecnico di Torino Corso Duca degli Abruzzi 24, 10129 Torino, Italy; fax: +39 0131 229337; e-mail: jenny.alongi@polito.it

$2^{*}$ Dipartimento di Chimica e Chimica Industriale, Università di Genova and INSTM NIPLAB Centre, Via Dodecaneso 31, 16146 Genova, Italy; fax: +39 010353 6198, email: orietta@chimica.unige.it, russo@chimica.unige.it

3 Laboratoire des Matériaux Macromoléculaires/IMP UMR CNRS 5627, Institut National des Sciences Appliquées de Lyon, 20 Av. Albert Einstein, 69621 Villeurbanne Cedex, France ; fax : +33 04724385 27, e-mail: jocelyne.galy@insalyon.fr, jean-francois.gerard@insa-lyon.fr

(Received: 14 August, 2008; published: 09 March, 2009)

\begin{abstract}
Preparation of inorganic-organic hybrids made of polyhedral oligomeric silsesquioxanes (POSS) and polyamide 6 (PA6) has been attempted either by melt mixing of the two components or by in-situ polymerization of $\varepsilon$-caprolactam (CL) in presence of POSS. The samples have been characterized by wide angle $X$-ray diffraction (WAXD) and scanning electron microscopy (SEM) techniques. Specific processing conditions (namely, high $\mathrm{T}$ in presence of different shear stresses) have been tested. Two different approaches for melt mixing have been used and the morphology of the corresponding systems compared. The melt-mixed pairs prepared in the microcompounder revealed a coarse phase separation, while those made in a simple mixer did not show any perceivable POSS segregation phenomenon, as evidenced by both WAXD data and SEM investigation. Similarly, the in-situ polymerization of CL in presence of POSS did not result in any POSS self-aggregation in the polyamide matrix, achieving a very fine $\mathrm{Si}$ dispersion of nanometric dimensions.
\end{abstract}

\section{Introduction}

In the framework of the rapidly developing fields of nanoscience and nanotechnology, the domain of nanostructured materials is attracting more and more research groups, both at academic and industrial level. Among the nanostructured materials, polymerbased inorganic-organic hybrids, including nanocomposites, play a very relevant role. The properties of nanostructured hybrid systems strongly depend on the uniform dispersion of fillers having at least one dimension less than $100 \mathrm{~nm}$ in the polymer matrix. The rise of this new area of interest is mainly linked to some important advantages that the above class of materials shows in comparison to traditional polymer composites. 
Among the nanostructured organic-inorganic materials, polyhedral oligomeric silsesquioxanes (POSS) are increasingly adopted and developed (Schwab et al. [1], Li et al. [2], Joshi et al. [3], Phillips et al. [4]). POSS molecules are characterized by a 3D cage nanostructure that can be more or less easily incorporated in suitable polymer matrices, giving rise to hybrid systems. The great interest for POSS-based nanostructures is linked to the relevant improvement of several properties of the polymer matrix, leading to much better performances of the resultant materials. If compared to the neat polymer, POSS-based polymer systems are characterized by lower dielectric constants (Leu et al. [5]), higher glass transition temperatures (Xu et al. [6], Huang et al. [7], Chen et al. [8]), better thermal stability (Kim et al. [9], Yei et al. [10]), significantly higher moduli (Pyun et al. [11]), higher oxidation resistance (Zheng et al. [12]), lower flammability (Lichtenhan et al. [13], Fina et al. [14], [15], [16]), in some cases higher permeability to gases (Schwab et al. [17] Böhning et al. [18]).

However, very fine inclusion of POSS in polymer matrices, by either its physical dispersion or a chemical link, is quite often a complex process to realize. Indeed, POSS coarse self-aggregation and phase separation into crystalline domains are commonly reported in literature [19-28] and widely prevent its nanometric dispersion in the polymer matrix. POSS molecules seem to prefer to aggregate or crystallize, thus forming organized structures which can reach $\mu \mathrm{m}$-size dimensions in the polymer matrix (Zheng et al. [19]). When this happens, the resultant morphology negatively affects the properties of the pair system.

As mentioned above, several papers are present in literature on the self-aggregation of POSS molecules. In the following, the most relevant contributions are briefly reviewed. Zheng et al. [19], Li et al. [20], Waddon et al. [21] prepared nanocomposites by incorporating pendant POSS into polyethylene (PE) matrix by copolymerization: the POSS units, attached to the polyethylene backbones, have been found to aggregate and crystallize as nanocrystals, forming a lattice well separated from the PE lattice with its characteristic diffraction signals. Indeed, X-ray investigation revealed that the above nanocomposites were characterized by distinct populations of crystalline PE and crystalline POSS domains. New organic-inorganic systems prepared from a resol phenolic resin and trisilanolphenyl-POSS have been studied by Li et al. [20]. Pairs containing 1.0 $\div 10.4$ wt.-\% of POSS showed nano- and micro-sized POSS aggregates and particles. Polarized optical microscopy (POM), TEM and SEM, coupled to energy dispersive spectroscopy (EDS), pointed out to a heterogeneous dispersion of the inorganic filler in the cured matrix. The composite morphology appeared to be formed by a multi-step POSS aggregation during phase separation. Both the matrix and the dispersed inorganic phase domains were, indeed, mixtures of the phenolic resin and POSS. POSS microcrystals acted as the core of the dispersed phase. The larger domains consisted of smaller particles or aggregates of POSS molecules that exhibited some order, as evidenced by WAXD. Indeed, a characteristic peak at $2 \theta$ of $7.3^{\circ}$ pointed out to the presence of some crystalline order. The peak intensity increased by increasing POSS loading, emphasizing the tendency of more and more POSS molecules to undergo selfaggregation and crystallization. Also Abad et al. [22] observed an aggregation phenomenon when incorporating POSS containing an epoxy group and seven isobutyl groups per molecule into an epoxy network.

The possibility to suppress the aggregation phenomenon of POSS has been investigated by choosing suitable experimental conditions and changing POSS type (namely, POSS with norbornene and cyclopentyl side groups, Waddon et al. [21]). 
Matějka et al. [23], and Strachota et al. [24] modified epoxy-amine networks with well-defined inorganic building blocks of POSS. POSS molecules were incorporated in the organic-inorganic networks as dangling units of the network chain or as network junctions. Mono- or polyepoxide POSS monomers have been used to prepare the two types of networks. The structure of the POSS-containing networks has been determined by small and wide angle X-ray diffraction, as well as TEM. POSS pendant groups from a network chain showed a strong tendency toward aggregation and crystallization, specifically depending on POSS organic ligands. During network formation, ordering of the crystal domains took place. Poly(ethylene terephthalate) (PET) containing epoxy-functionalized POSS has been prepared by Yoon et al. [25] by either melt mixing or in-situ polymerization methods. The meltmixed hybrids showed phase separation, while the in-situ polymerized pairs did not, as evidenced by SEM investigation. During melt mixing, reactions between the POSS epoxy groups and PET hydroxyl groups occurred, as shown by DSC. Ma and Li [26] prepared epoxy-cyanate ester hybrids containing octaisobutyl-POSS. Transmission electron microscopy micrographs and WAXD patterns showed silica aggregates micrometrically dispersed in the matrix. Lee et al. [28] prepared a new class of polybenzoxazine/POSS hybrids, characterized by a network structure, by reacting multifunctional POSS with benzoxazine monomers at various compositional ratios. For these pairs, atomic force microscopy (AFM) data showed the presence of POSS aggregates having larger dimensions at higher POSS contents: silica-rich domains in the range of 50-1000 $\mathrm{nm}$ were clearly evident.

In the present study, we will present how to prepare and characterize PA6/POSS pairs (forming nanosized hybrids in the optimum conditions) by melt mixing of the components in a microcompounder or in a simple mixer at high temperature. In order to promote strong interactions and/or chemical reactions between the polymer matrix and POSS, suitable epoxy-POSS molecules as well as proper experimental conditions have been chosen. Comparison between microcompounder and simple mixer experiments has been made keeping constant both the temperature and the contact time, with the aim of clarifying the role of environment control, as well as of different levels of shear stress, on possible oxidative reactions on PA6 and/or PA6POSS pairs. Moreover, the end properties of hybrid materials prepared by melt mixing have been compared to those of the systems made by in-situ polymerization of $\varepsilon$-caprolactam in presence of the same POSS molecules.

\section{Results and discussion}

\section{PA6-POSS systems prepared in a microcompounder}

Thermal stability of our epoxy-POSS molecules in inert atmosphere has been preliminarily checked by TGA. The corresponding curves are given in Figure 1.

Both structures turned out to be stable at the temperature of processing, i.e. $250{ }^{\circ} \mathrm{C}$; namely at this temperature the weight loss is negligible (ca. 0.7 and $0.3 \mathrm{wt} .-\%$, respectively, for EPO402 and EPO408). Thus, hybrid samples have been prepared by mixing polyamide 6 and epoxy-POSS in a microcompounder at different experimental conditions: mixing rate, residence time and reactant pair characteristics were varied. As far as the latter point is concerned, as mentioned in the Experimental, two types of PA6 characterized by different molar masses, and two types of epoxy-POSS were used. In fact, the main purpose of this part of our study has been to verify the POSS dispersion level within the polymer matrix and the 
possible adhesion between the inorganic filler and the polymer in the experimental processing conditions (i.e. high temperature in presence of some shear stress).

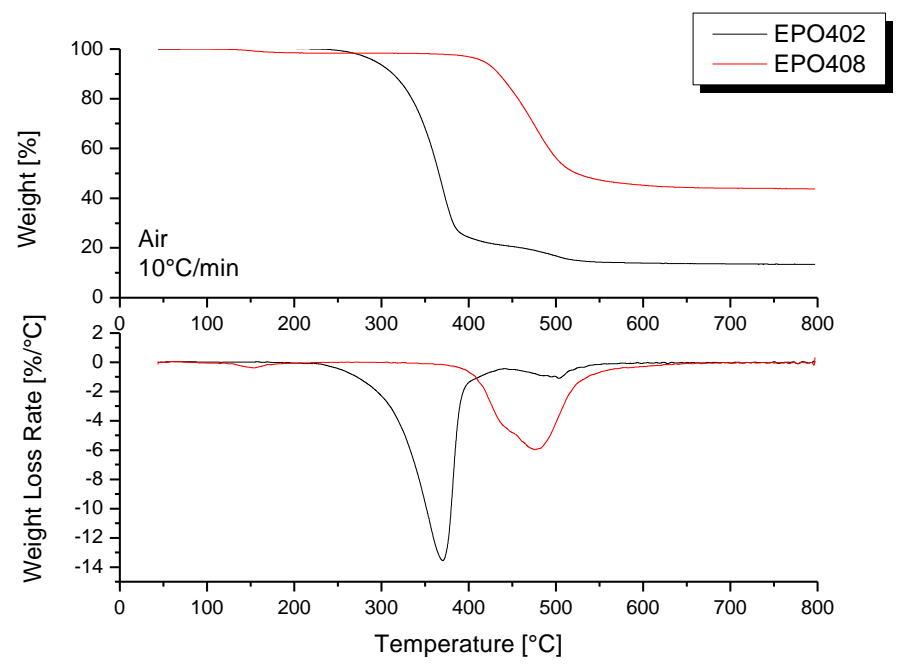

Fig. 1. Thermogravimetric curves of epoxy-POSS molecules.

Tab. 1. Characteristics of PA6/epoxy-POSS samples prepared in the microcompounder at $v=40 \mathrm{rpm}$ (contact time $=10 \mathrm{~min}$ ) as functions of POSS type and content for the two PA6 samples.

\begin{tabular}{|c|c|c|c|c|}
\hline $\begin{array}{l}\text { sample } \\
\text { code }\end{array}$ & $\begin{array}{l}\text { POSS } \\
\text { type }\end{array}$ & polyamide type & POSS content (wt.-\%) & $\begin{array}{l}\text { level of POSS } \\
\text { dispersion }\end{array}$ \\
\hline JA1 & EPO402 & ULTRAMID ${ }^{\circledR}$ B40 & 1 & 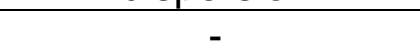 \\
\hline JA2 & EPO402 & ULTRAMID ${ }^{\circledR}$ B40 & 2 & 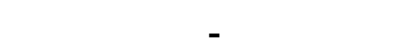 \\
\hline JA3 & EPO402 & ULTRAMID ${ }^{\circledR} \mathrm{B} 40$ & 5 & aggregates (ca. $6 \mu \mathrm{m}$ ) \\
\hline JA4 & EPO402 & ULTRAMID ${ }^{\circledR}$ B40 & 10 & 4 \\
\hline JA5 & EPO408 & ULTRAMID ${ }^{\circledR}$ B40 & 1 & - \\
\hline JA6 & EPO408 & ULTRAMID ${ }^{\circledR}$ B40 & 2 & - \\
\hline JA7 & EPO408 & ULTRAMID ${ }^{\circledR} \mathrm{B} 40$ & 5 & aggregates \\
\hline JA8 & EPO408 & ULTRAMID ${ }^{\circledR} \mathrm{B} 40$ & 10 & \\
\hline JA17 & EPO402 & TECHNYL ${ }^{\circledR} \mathrm{S} 27$ & 1 & - \\
\hline JA18 & EPO402 & TECHNYL ${ }^{\circledR} S 27$ & 2 & \\
\hline JA19 & EPO402 & TECHNYL ${ }^{\circledR} \mathrm{S} 27$ & 5 & $\begin{array}{c}\text { small aggregates } \\
\text { (ca } 4 \text { um) }\end{array}$ \\
\hline $\begin{array}{l}\text { JA20 } \\
\text { JA21 } \\
\text { JA22 }\end{array}$ & $\begin{array}{l}\text { EPO402 } \\
\text { EPO408 } \\
\text { EPO408 }\end{array}$ & $\begin{array}{l}\text { TECHNYL L }{ }^{\circledR} S 27 \\
\text { TECHNYL }{ }^{\circledR} \text { S } 27 \\
\text { TECHNYL }{ }^{{ }^{S}} \text { S27 }\end{array}$ & $\begin{array}{c}10 \\
1 \\
2\end{array}$ & - \\
\hline JA23 & EPO408 & TECHNYL ${ }^{\circledR} \mathrm{S} 27$ & 5 & large aggregates \\
\hline JA24 & EPO408 & TECHNYL ${ }^{\circledR} \mathrm{S} 27$ & 10 & f \\
\hline
\end{tabular}

Tables 1-3 give the characteristics of the samples prepared in the microcompounder at different experimental conditions. Table 1 collects data, referred to $v=40 \mathrm{rpm}$ and 
contact time $=10 \mathrm{~min}$, for the pairs based on the two PA6 samples as functions of POSS type and content. For comparison, other two series of samples have been prepared varying mixing rate and/or contact time.

Tab. 2. Characteristics of PA6/epoxy-POSS samples prepared in the microcompounder at $v=80 \mathrm{rpm}$ (contact time $=30 \mathrm{~min}$ ) as functions of POSS type and content for two PA6 samples.

\begin{tabular}{|c|c|c|c|c|}
\hline $\begin{array}{l}\text { sample } \\
\text { code }\end{array}$ & $\begin{array}{l}\text { POSS } \\
\text { type }\end{array}$ & polyamide type & POSS content (wt.-\%) & $\begin{array}{c}\text { level of POSS } \\
\text { dispersion }\end{array}$ \\
\hline JA9 & EPO402 & ULTRAMID ${ }^{\circledR}$ B40 & 1 & - \\
\hline JA10 & EPO402 & ULTRAMID ${ }^{(B)}$ B40 & 2 & - \\
\hline JA11 & EPO402 & ULTRAMID ${ }^{\circledR}$ B40 & 5 & $\begin{array}{c}\text { small aggregates } \\
\text { (ca. } 5 \mu \mathrm{m})\end{array}$ \\
\hline JA12 & EPO402 & ULTRAMID ${ }^{\circledR} \mathrm{B} 40$ & 10 & - \\
\hline JA13 & EPO408 & ULTRAMID ${ }^{\circledR} \mathrm{B} 40$ & 1 & - \\
\hline JA14 & EPO408 & ULTRAMID ${ }^{\circledR}$ B40 & 2 & - \\
\hline JA15 & EPO408 & ULTRAMID ${ }^{\circledR} \mathrm{B} 40$ & 5 & large aggregates \\
\hline JA16 & EPO408 & ULTRAMID ${ }^{\circledR} \mathrm{B} 40$ & 10 & голтіл \\
\hline JA25 & EPO402 & TECHNYL ${ }^{\circledR} \mathrm{S} 27$ & 1 & - \\
\hline JA26 & EPO402 & TECHNYL ${ }^{\circledR} \mathrm{S} 27$ & 2 & 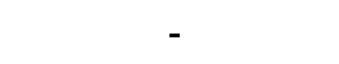 \\
\hline JA27 & EPO402 & TECHNYL ${ }^{\circledR} \mathrm{S} 27$ & 5 & $\begin{array}{c}\text { small aggregates } \\
\text { (ca. } 2 \mathrm{um} \text { ) }\end{array}$ \\
\hline JA28 & EPO402 & TECHNYL ${ }^{\circledR} \mathrm{S} 27$ & 10 & - \\
\hline JA29 & EPO408 & TECHNYL ${ }^{\circledR} \mathrm{S} 27$ & 1 & - \\
\hline JA30 & EPO408 & TECHNYL ${ }^{\circledR} \mathrm{S} 27$ & 2 & - \\
\hline JA31 & EPO408 & TECHNYL ${ }^{\circledR} \mathrm{S} 27$ & 5 & - \\
\hline JA32 & EPO408 & TECHNYL ${ }^{\circledR} \mathrm{S} 27$ & 10 & - \\
\hline
\end{tabular}

Table 2 gives data referred to $\mathrm{v}=80 \mathrm{rpm}$ and contact time of $30 \mathrm{~min}$, while Table 3 refers to samples obtained by decreasing the mixing rate $(\mathrm{v}=20 \mathrm{rpm})$, and maintaining the same contact time of 10 min used in the first series of runs.

Let us explain the rationale behind the above choice of the experimental conditions: the morphological analysis by SEM, performed on the first series of samples (Table 1 ), has evidenced a rather coarse dispersion of POSS in the polymer matrix (see later). Samples prepared in the conditions given in Table 2 could in principle show a more intimate contact between the polyamide and POSS because of the increase of both the mixing rate and the contact time.

As the latter approach was not effective at all, the experimental set up in the following run has been totally changed by decreasing only the mixing speed and keeping the contact time between the two species the same as for the first runs ( $v=20 \mathrm{rpm}$, contact time $=10 \mathrm{~min}$ ).

As anticipated above, SEM investigation, coupled to EDS analysis, has allowed to study the morphology of the various organic-inorganic systems prepared in the microcompounder, paying specific attention to Si dispersion, i.e. POSS distribution, in the polymer matrix. All micrographs shown in the present paper are referred to 
PA6/POSS samples containing 5 wt.- $\%$ of POSS, i.e. a value close to the typical amount used in general for nanocomposite preparation.

Tab. 3. Characteristics of PA6/epoxy-POSS samples prepared in the microcompounder at $\mathrm{v}=20 \mathrm{rpm}$ (contact time $=10 \mathrm{~min}$ ) as functions of POSS content (POSS: EPO402; PA6: TECHNYL ${ }^{\circledR}$ S27).

\begin{tabular}{ccc}
\hline sample code & POSS content (wt.-\%) & $\begin{array}{c}\text { level of POSS } \\
\text { dispersion }\end{array}$ \\
\hline JA46 & 2 & - \\
JA47 & 5 & aggregates \\
JA48 & 10 & (ca. $8 \mu \mathrm{m})$ \\
\hline
\end{tabular}

other experimental conditions: $\mathrm{T}_{\text {mixing }}=250^{\circ} \mathrm{C}$, nitrogen blanket

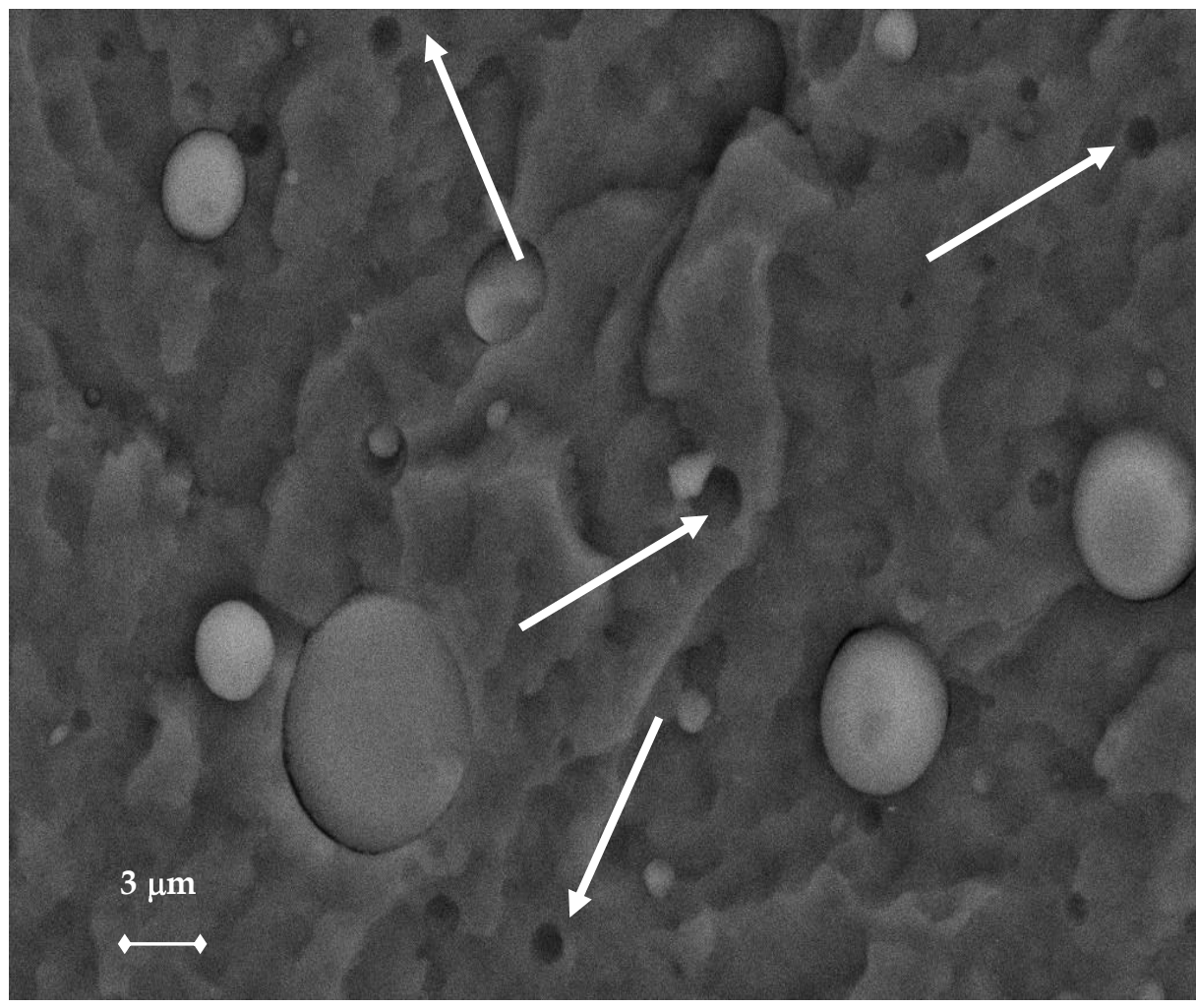

Fig. 2. SEM micrograph of the sample JA3.

Samples containing lower (1 and 2 wt.-\%) or higher POSS concentration (10 wt.-\%) gave similar results.

Figure 2 shows the micrograph of sample JA3 based on ULTRAMID ${ }^{\circledR} \mathrm{B} 40$ and EPO402, i.e. a POSS characterized by a single epoxy group. The above micrograph, also supported by EDS analysis, shows the presence of large, quasi-spherical aggregates of POSS dispersed in the polymer matrix. Moreover, several holes (pointed out by the white arrows) are distributed on the polymer surface. They are due to the removal of POSS aggregates during sample fracture, and give evidence of the scarce adhesion of POSS to PA6. 
Other micrographs (not given) show that, when increasing POSS concentration in the mixture, the dimensions of Si aggregates tend to increase. In the case of sample JA7 based on multifunctional epoxy-POSS, i.e. EPO408, the filler segregation (Figure 3) is even more evident and hole diameters are of ca. $45 \mu \mathrm{m}$.

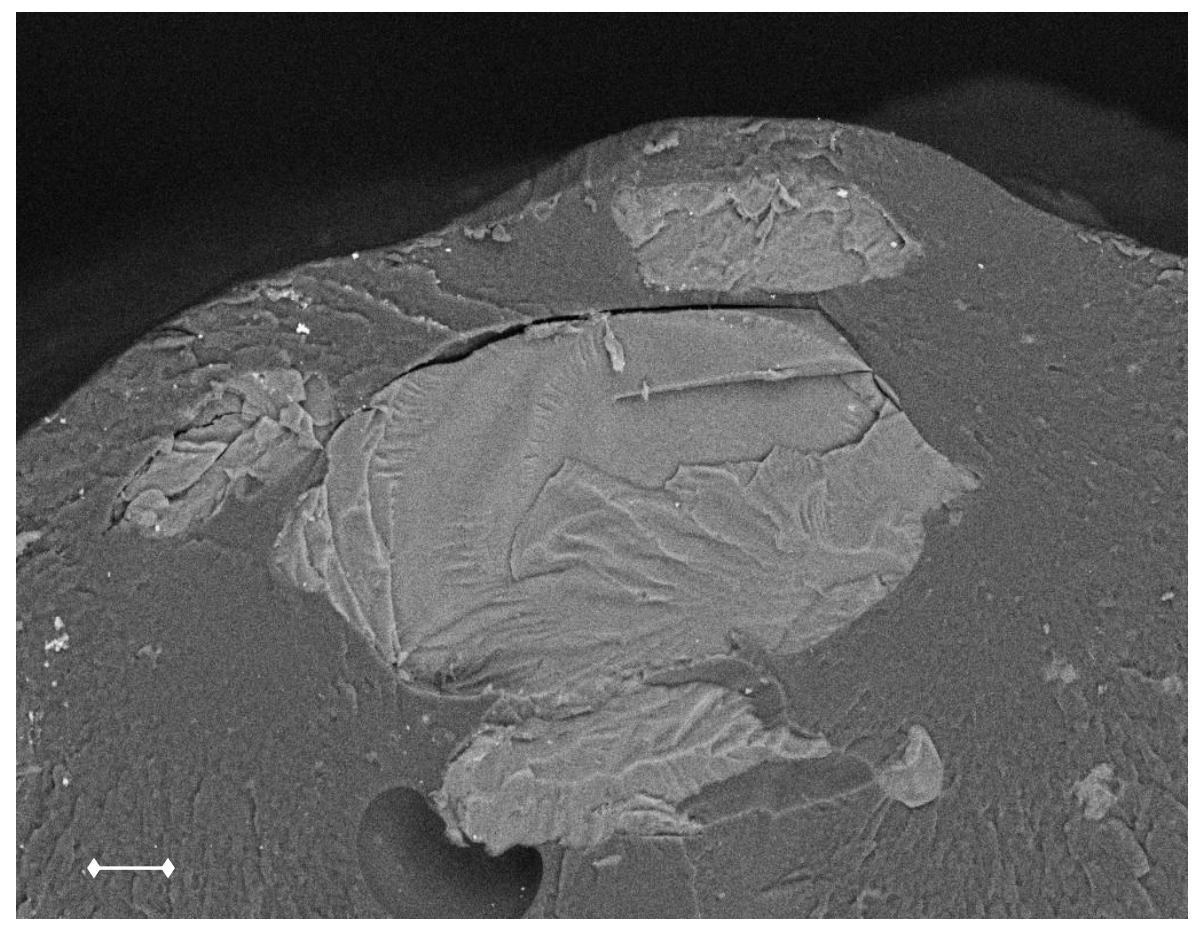

Fig. 3. SEM micrograph of the sample JA7

As previously reported, samples of the pair system have also been prepared from TECHNYL ${ }^{\circledR}$ S27, a PA6 characterized by a molar mass lower than that of ULTRAMID ${ }^{\circledR}$ B40 described above. Once again, the comparison between SEM micrographs of the composite samples based on EPO408 (JA23, not shown) and EPO402 (JA19) (Figure 4) reveals that the former shows POSS aggregates characterized by higher dimensions (ca.10 $\mu \mathrm{m}$ ) than those of the latter (ca. $4 \mu \mathrm{m})$.

In order to explain the above differences, it is relevant to remind that the multifunctional POSS is characterized by a large presence of impurities (ca. 40 wt.$\%)$ with an open resin-like structure (see later), which should strongly limit the solubilization and the interactions of POSS molecules with PA6. However, with respect to samples made from ULTRAMID ${ }^{\circledR} B 40$, a decrease of the aggregate dimensions is evident when a comparison between Figures 2 and 4 is carried out. This phenomenon is most probably linked to the lower melt viscosity of TECHNYL ${ }^{\circledR}$ S27, as compared to ULTRAMID ${ }^{\circledR}$ B40, thus helping the solubilization of POSS and consequently forming a less coarse dispersion of it in the polymer matrix.

As mentioned above, the influence of experimental processing conditions, namely mixing rate and contact time, on morphological characteristics of the pair system has been evaluated. The samples JA11 and JA15 have been prepared by using a higher rate and contact time, i.e. $80 \mathrm{rpm}$ and $30 \mathrm{~min}$, as compared to the conditions applied for the preparation of the corresponding samples previously mentioned (i.e. JA3 and $\mathrm{JA} 7, \mathrm{v}=40 \mathrm{rpm}$ and contact time $=10 \mathrm{~min}$ ). 


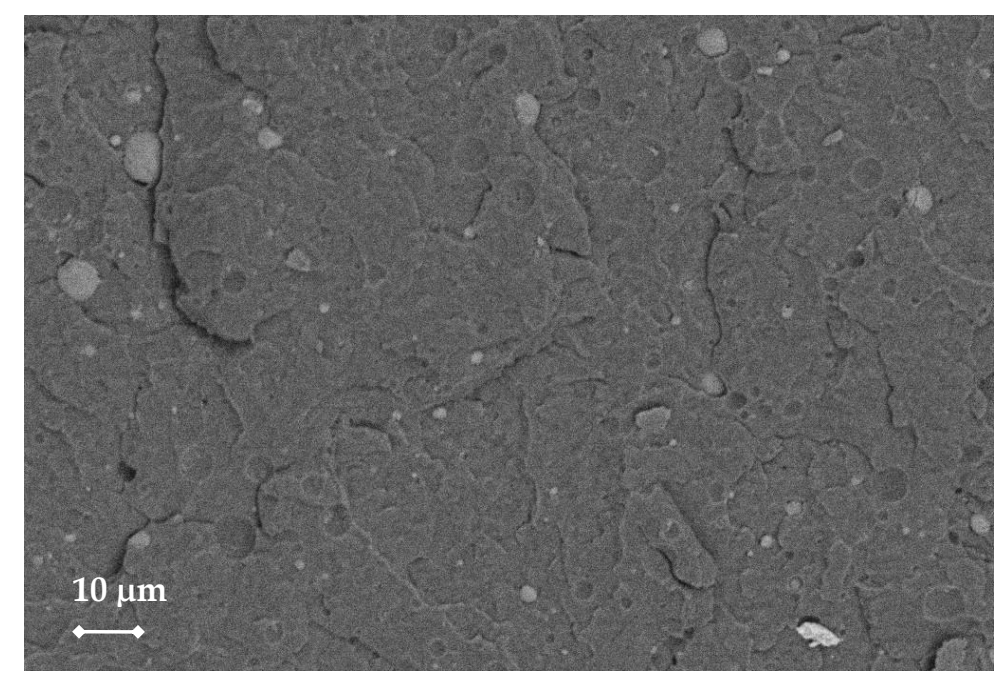

Fig. 4. SEM micrograph of the sample JA19.

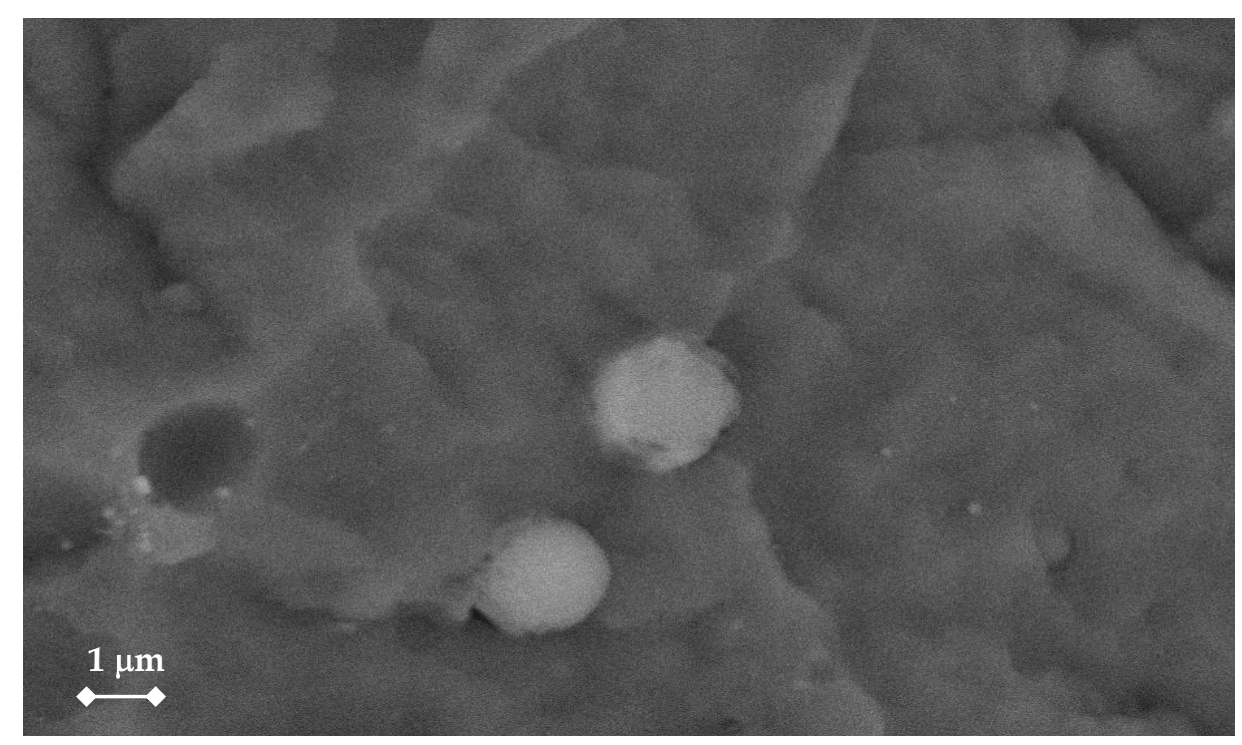

Fig. 5. SEM micrograph of the sample JA27 (SE emission).

Both series of samples are based on ULTRAMID ${ }^{\circledR} \mathrm{B} 40$, and have been made from mono- or multi-functional POSS, respectively. Comparing the SEM data (not given) to those obtained for the samples JA3 and JA7, a reduction of POSS aggregate dimensions in JA11 and JA15 was evident. Also in this case, multi-functional POSS (JA15) showed the worst dispersion and the worst adhesion to the polymer matrix.

When considering the samples prepared with TECHNYL ${ }^{\circledR}$ S27 (JA27 in Figure 5, and JA31, not given), SEM micrographs do not show any further improvement of the POSS dispersion, as compared to the systems based on higher molar mass PA6.

On the basis of the above results, some pair samples (namely, JA46, JA47, JA48) have been prepared only by varying the speed $(20 \mathrm{rpm})$ and keeping the same contact time (10 min.) adopted for the preparation of samples JA18, JA19 and JA20, in order to evaluate the role of the shear rate parameter on Si dispersion. Only monofunctional POSS and the low molar mass PA6 have been used for this purpose. 
SEM analysis (Figure 6) shows that, also in the case of sample JA47, monofunctional POSS has been dispersed only at micrometric level. Back scattering (BS) analysis (Figure 6b) confirms that white aggregates (evidenced by secondary electron (SE) analysis, Figure 6a) consist of Si. Also for this sample, as for sample JA19 (Figure 4), the dimension (diameter) of aggregates is ca. $4 \mu \mathrm{m}$.

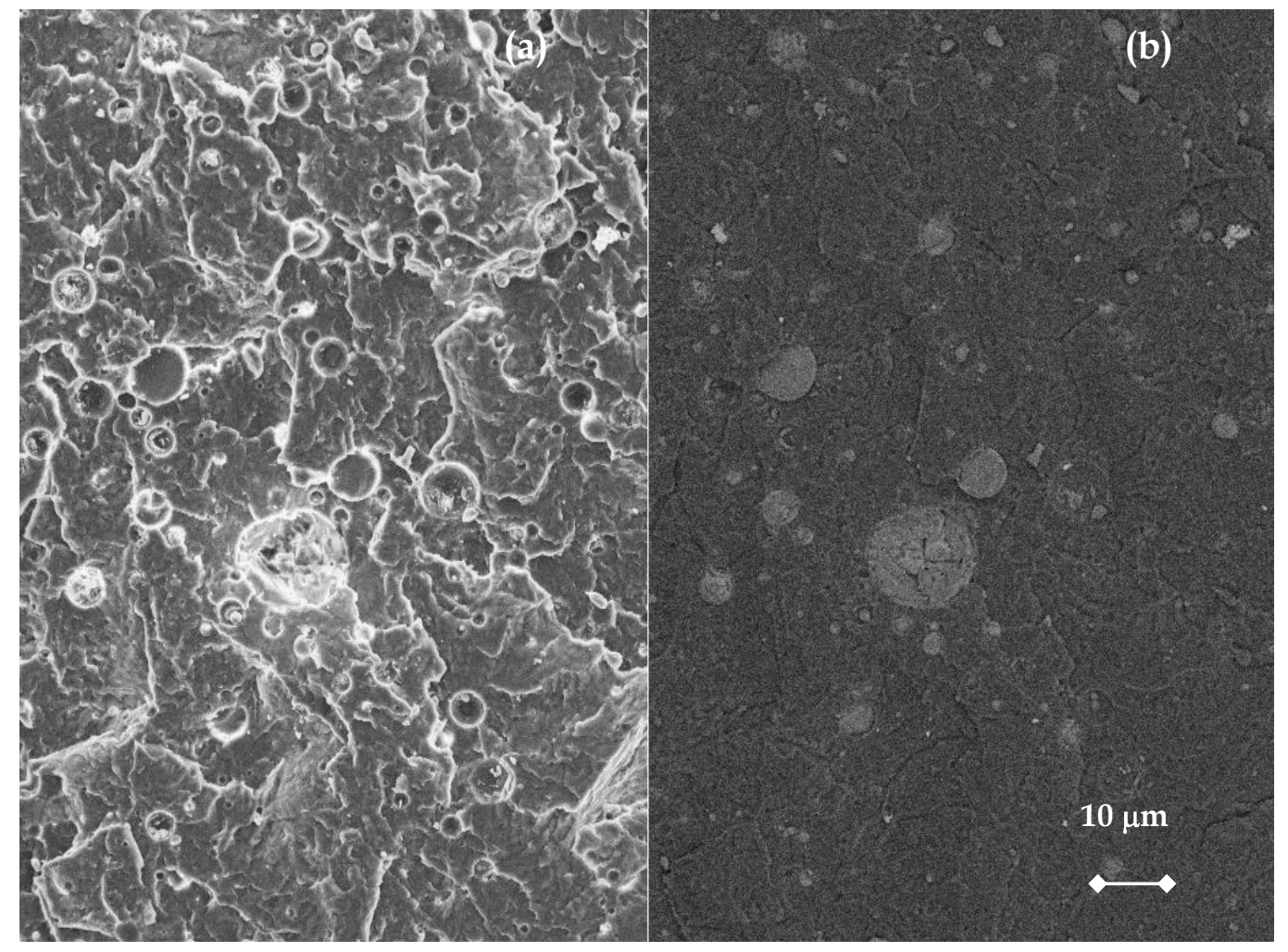

Fig. 6. SEM micrograph of the sample JA47 by (a) SE and (b) BS emission.

It can be concluded that, by this method of mixing, only micrometer dispersions are obtained in all experimental conditions chosen.

\section{PA6-POSS hybrid systems prepared in a mixer}

A simple mixer capable to mimic the melt mixing process performed in the microcompounder, namely by working at the same temperature and contact time, has been used to prepare PA6/POSS systems in an alternative way. This method, based on better controlled conditions (inert atmosphere, homogeneous distribution of temperature throughout the sample, good material contact, etc.) than those used above for compounding, can provide a useful piece of information on the feasibility of nanostructured material formation by properly changing and carefully controlling the experimental parameters. Table 4 summarizes the characteristics of samples prepared in the mixer as functions of monofunctional epoxy-POSS content at various experimental conditions.

Figure 7 shows a SEM micrograph, obtained by SE (a) and BS emission (b), of the sample JA39 made of TECHNYL ${ }^{\circledR}$ S27 and EPO402 (5 wt.-\%) which is analog in composition to JA19 and JA27 prepared by the microcompounder. Similar micrographs (not given) have also been obtained for the sample JA40, prepared using a longer time of mixing. Analyzing the micrographs of Figure 7 , it comes out 
that the sample JA39 does not show Si aggregates, suggesting a likely formation of nanostructured materials.

Tab. 4. Characteristics of PA6/epoxy-POSS samples prepared in the mixer as functions of POSS content at various set-up conditions (POSS: EPO402; PA6: TECHNYL $\left.{ }^{\circledR} \mathrm{S} 27\right)$.

\begin{tabular}{|c|c|c|c|}
\hline sample code & POSS content (wt.-\%) & time of mixing & $\begin{array}{l}\text { level of POSS } \\
\text { dispersion }\end{array}$ \\
\hline JA39 & 5 & $30 \mathrm{~min}$ & $\begin{array}{c}\text { nanodispersion } \\
+ \text { very small } \\
\text { aggregates }(<1 \\
\mu \mathrm{m})\end{array}$ \\
\hline JA40 & 5 & $60 \mathrm{~min}$ & $\begin{array}{l}\text { nanodispersion } \\
\text { nanodispersion }\end{array}$ \\
\hline JA41 & 5 & $30 \min ^{*}$ & $\begin{array}{c}+ \text { very small } \\
\text { aggregates }(<1 \\
\mu \mathrm{m})\end{array}$ \\
\hline
\end{tabular}

" fast cooling

In the light of the results described so far, it is reasonable to conclude that a simple melt mixer is much more effective than a microcompounder in order to obtain a good POSS dispersion in the polymer matrix. As already foreseen, this difference might be linked to various factors such as a better control of both temperature and mixing efficiency in the mixer, as well as POSS evaporation-condensation cycles in the closed chamber of the mixer favouring its homogeneous dispersion.

Besides SEM analysis, also X-ray characterization data can provide useful information on the level of POSS dispersion in the polymer matrix.

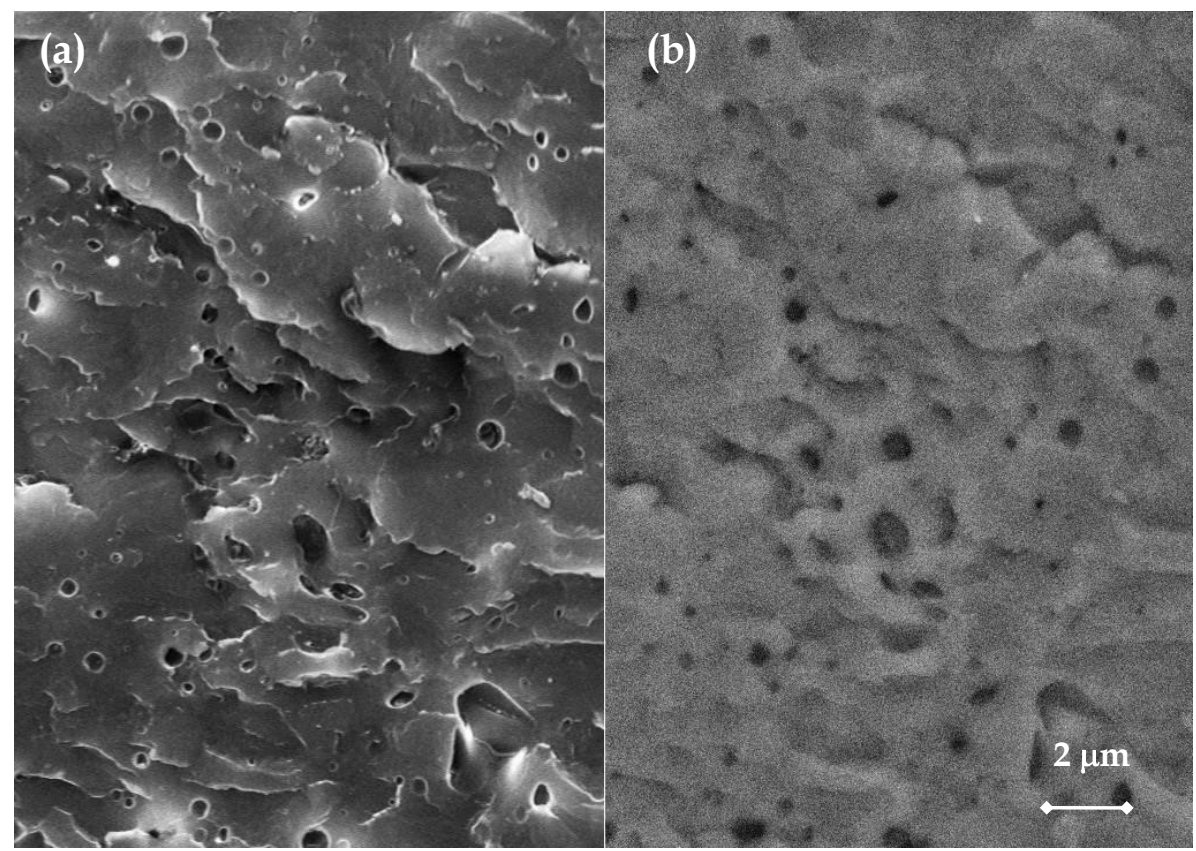

Fig. 7. SEM micrograph of the sample JA39 by (a) SE and (b) BS emission. 
Figure 8 shows X-ray diffraction patterns of samples JA39 and JA40. In the diffractogram of JA39, together with the reflections due to PA6 (in the region from 20 to $30^{\circ}$ of $2 \theta$ ) it is possible to distinguish a small reflection at $c a$. $8^{\circ}$ of $2 \theta$, which is due to the crystalline lattice of POSS molecules, while the WAXD pattern of the sample JA40 does not show any peak at low angles. The presence of the above peak in sample JA39 should be due to very small POSS aggregates, which can keep their crystalline organization.

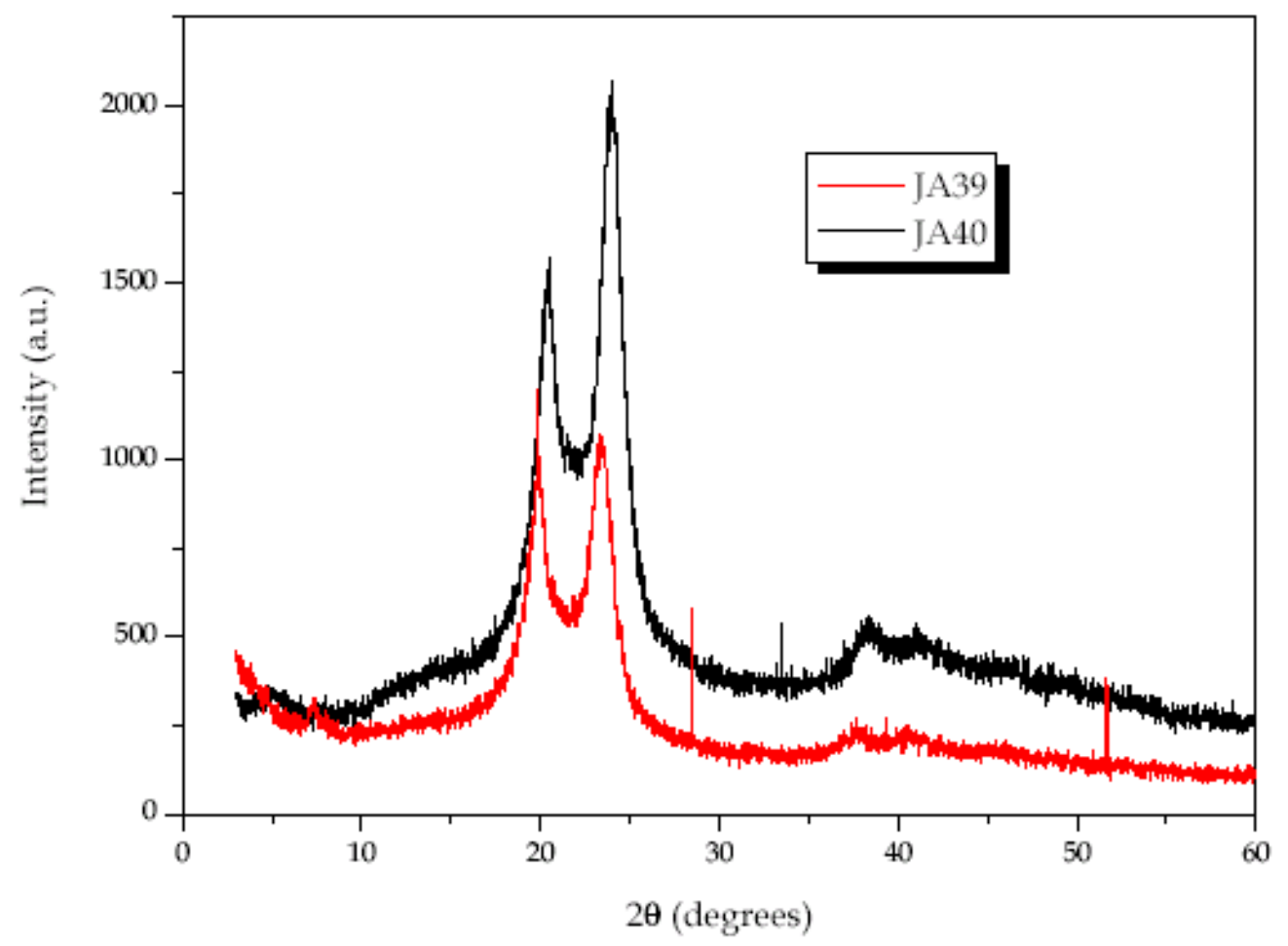

Fig. 8. WAXD patterns of the samples JA39 and JA40.

We can conclude that doubling the mixing time effectively leads to a homogeneous dispersion of POSS in the PA6 matrix. Very similar results, not given, have been found with other samples of this series.

It is relevant to point out that a similar lattice organization of POSS has already been found in another nanostructured material, i.e. the nanocomposite based on PE (Zheng et al. [19]). As mentioned in the introduction, POSS units, incorporated as pendant groups from the PE backbone, turned out to self-aggregate and crystallize as nanocrystals. On these grounds, WAXD characterization has always to be taken in account in close relationship to SEM analysis, that alone cannot reveal the presence of very small clusters of POSS.

From the considerations reported above, it can be concluded that sample JA40, devoid of any reflection peak, should be characterized by a true nanodispersion of POSS moieties in PA6. At the same time, the sample JA39 prepared in the same conditions used in the microcompounder, i.e. $30 \mathrm{~min}$ and $250{ }^{\circ} \mathrm{C}$, although presumably characterized by some POSS aggregation as evidenced by the small peak at low $2 \theta$ angles, has a Si distribution much finer than that obtained for the corresponding system prepared in the microcompounder (cfr. sample JA27, Figure 
5). All these results underline a relevant influence of the aforementioned experimental conditions, in particular extensive time of mixing, and the need of their careful control on nanostructured material formation.

Another factor to consider can be linked to possible differences of the cooling rate after the mixing experiments between microcompounder samples, which are rapidly cooled to room temperature, and mixer samples that are more slowly cooled. Therefore, quick cooling of an additional sample prepared in the mixer (JA41) has been performed. SEM investigation coupled to EDS analysis (not given) has revealed that the dispersion of POSS in the polymer matrix was still nanometric and differences in the cooling rate were not able to affect the morphology of blends. Therefore, it can be asserted not only that mixing in the simple mixer is much more effective than that in the microcompounder for the preparation of a nanometric dispersion of POSS in PA6, but also that post-mixing cooling rate is not relevant in this respect.

\section{PA6-POSS hybrid systems by in-situ CL polymerization}

The properties of pair system samples prepared by high-T mixing of PA6 and epoxyPOSS have been compared to those of samples obtained by the in-situ hydrolytic polymerization of $\varepsilon$-caprolactam in presence of POSS, namely by adding POSS molecules to the polymerizing system at different polymerization times $(0 \mathrm{~h}, 1 \mathrm{~h}, 2 \mathrm{~h})$. Table 5 gives the experimental conditions chosen as functions of epoxy-POSS type (EPO402, EPO408), as well as EPO402 content (5, 10, 15 wt.-\%).

Tab. 5. Characteristics of PA6/epoxy-POSS samples prepared by in situ polymerization of $\mathrm{CL}$ as functions of POSS type and contact time at various experimental set-ups.

\begin{tabular}{|c|c|c|c|c|}
\hline Sample code & POSS type & $\begin{array}{l}\text { POSS } \\
\text { content } \\
\text { (wt.-\%) }\end{array}$ & note & $\begin{array}{l}\text { level of POSS } \\
\text { dispersion }\end{array}$ \\
\hline AJ1 & EPO402 & 5 & $\begin{array}{l}\text { POSS addition } \\
\text { after } 1 \mathrm{~h}\end{array}$ & nanodispersion \\
\hline AJ2 & EPO408 & 5 & $\begin{array}{l}\text { POSS addition } \\
\text { after } 1 \mathrm{~h}\end{array}$ & $\begin{array}{c}\text { small aggregates (ca. } \\
3 \mu \mathrm{m})\end{array}$ \\
\hline AJ3 & EPO402 & 5 & $\begin{array}{l}\text { POSS addition at } \\
\text { the beginning }\end{array}$ & - \\
\hline AJ4 & EPO402 & 5 & $\begin{array}{l}\text { POSS addition } \\
\text { after } 2 \mathrm{~h}\end{array}$ & - \\
\hline AJ6 & EPO402 & 10 & $\begin{array}{l}\text { POSS addition at } \\
\text { the beginning }\end{array}$ & nanodispersion \\
\hline AJ7 & EPO402 & 15 & $\begin{array}{l}\text { POSS addition at } \\
\text { the beginning }\end{array}$ & nanodispersion \\
\hline
\end{tabular}

SEM micrographs of the samples AJ1 and AJ2, obtained by SE and BS emission, are shown in Figures 9 and 10, respectively. The two POSS/PA6 pairs have been prepared by adding the mono-and multifunctional POSS, respectively, to the two polyamide growing chains (after $1 \mathrm{~h}$ from the start of CL polymerization). 


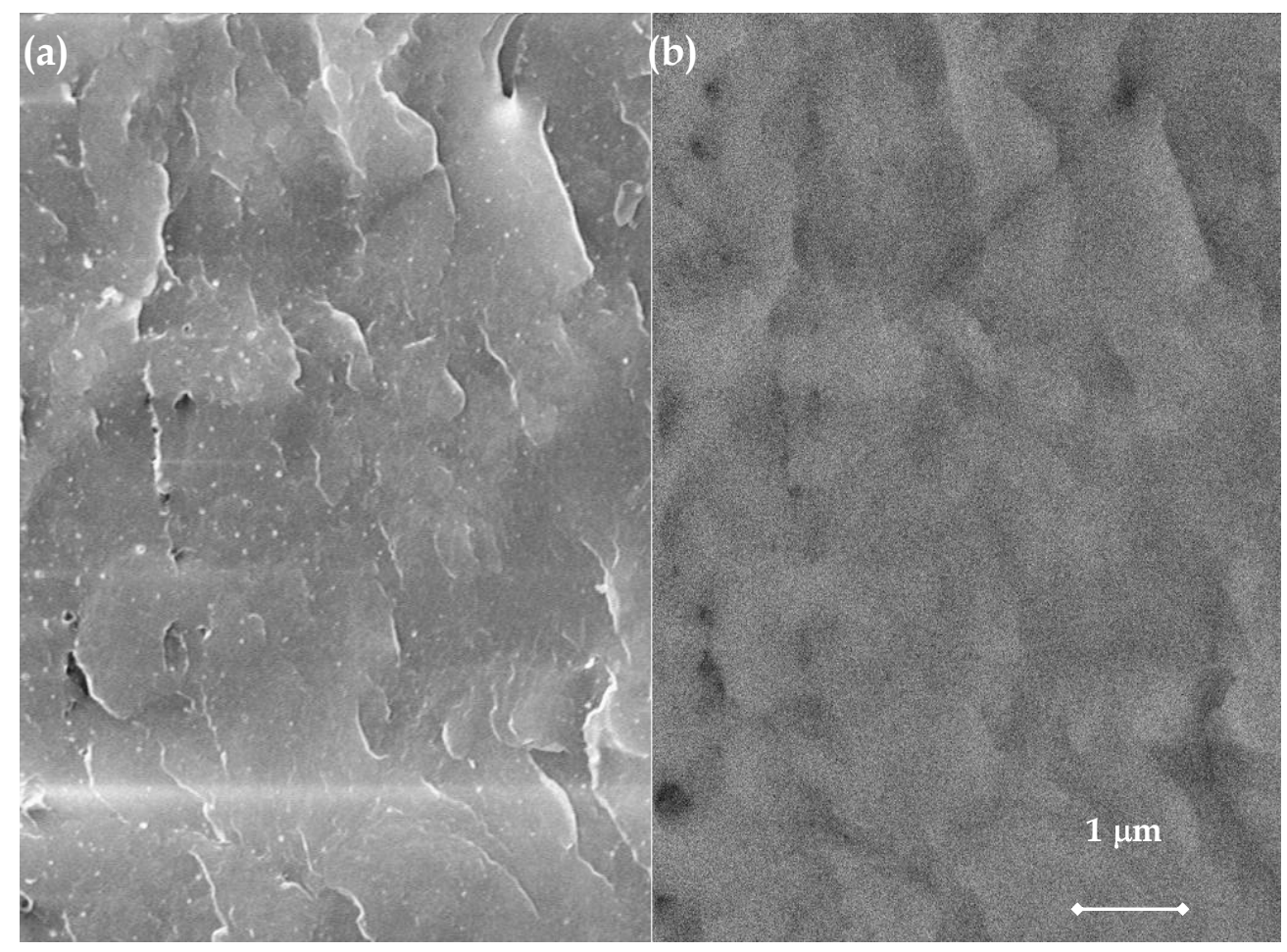

Fig. 9. SEM micrograph of the sample AJ1 by (a) SE and (b) BS emission.

While the former sample does not show any visible Si aggregates, a number of small aggregates are visible in the latter, as pointed out by the white arrows in Figure 10. As in the case of the sample prepared by melt mixing in the microcompounder (JA7, Figure 10), it is evident that EPO408 turns out to give again some self-aggregation in the polymer matrix.

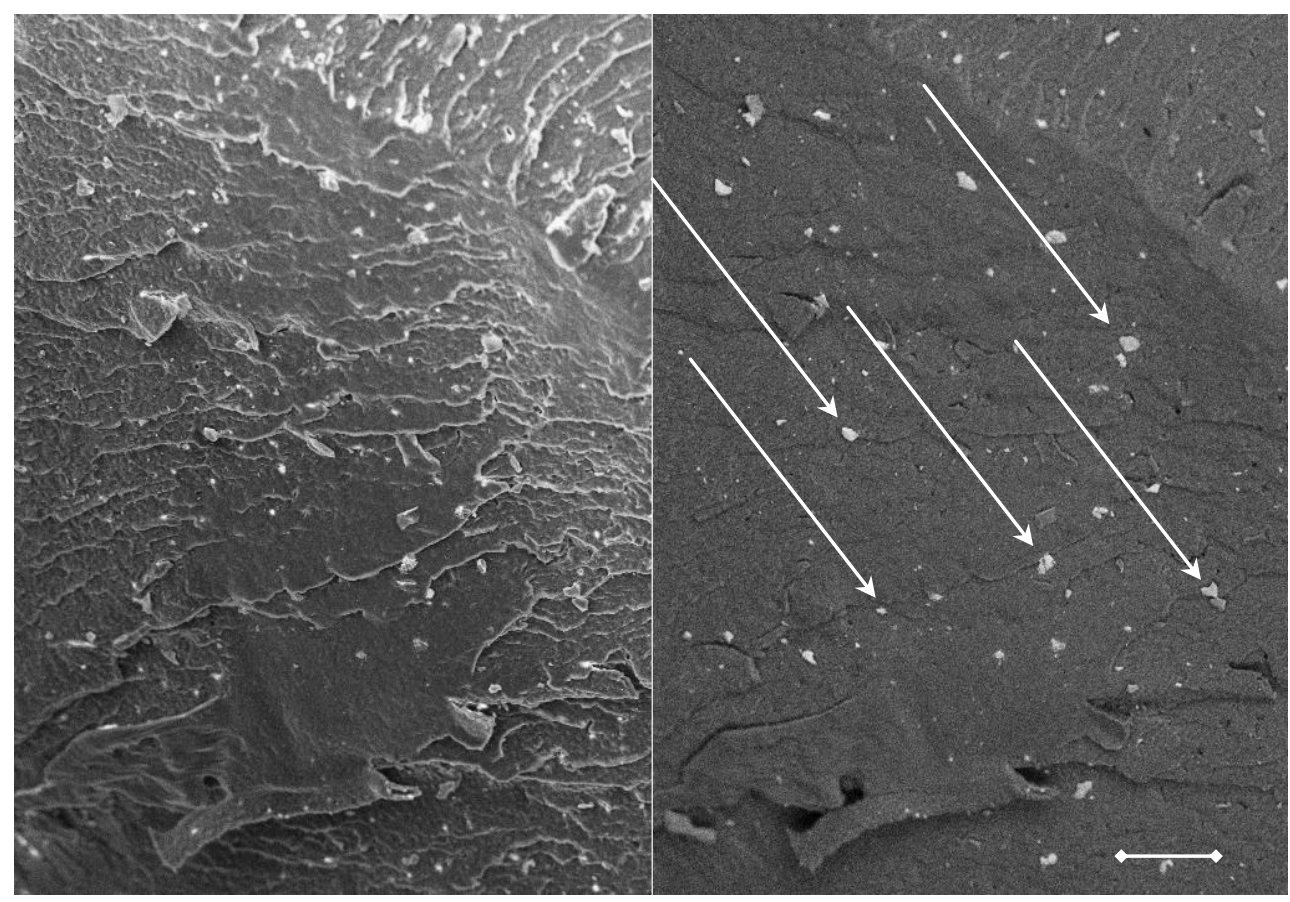

Fig. 10. SEM micrograph of the sample AJ2 by (a) SE and (b) BS emission. 
The fact that the above phenomenon might be due to the high level of impurities in EPO408 is pointed out by the scarce solubility of the above POSS in molten CL. In fact, while the monofunctional epoxy POSS is completely soluble in the molten CL monomer, EPO408 is soluble only in part.

It is relevant to point out that all samples based on EPO402 and prepared by adding POSS at different polymerization times (namely AJ3, AJ1 and AJ4, added at the beginning of polymerization, or after 1 and $2 \mathrm{~h}$, respectively) do not show any $\mathrm{Si}$ aggregation (micrographs not given). This result highlights the formation of a nanostructured material by either a direct insertion of POSS molecules in the PA6 chains or a production of soluble blends. Even if the POSS content is increased from 5 to 10 (AJ6) or 15 (AJ7) wt.-\%, a nanometric dispersion of $\mathrm{Si}$ is always obtained by this method, as pointed out by SEM investigation coupled to WAXD data (not given).

\section{Experimental part}

\section{Materials}

Two types of PA6 having different molar masses were used as polymer matrices: ULTRAMID ${ }^{\circledR}$ B40 supplied by BASF $\left(\mathrm{M}_{\mathrm{w}}=66,000,\left[-\mathrm{NH}_{2} /-\mathrm{COOH}\right]=1, \eta_{\mathrm{rel}}=4.0\right)$ and TECHNYL ${ }^{\circledR}$ S27 supplied by RHODIA $\left(\mathrm{M}_{\mathrm{w}}=37,500,\left[-\mathrm{NH}_{2} /-\mathrm{COOH}\right]=1, \eta_{\mathrm{rel}}=2.7\right)$.

POSS ${ }^{\circledR}$ samples, purchased from Hybrid Plastics, were two types of epoxy-POSS: epoxycyclohexylisobutyl-POSS (coded EPO402) with only an epoxy group, and epoxycyclohexyl-POSS (coded EPO408), which was not only a cage mixture of molecules with 8, 10, 12 epoxy groups (15, 67 and $18 \mathrm{wt} .-\%$, respectively), but it held also a relevant fraction of an open structure. In fact, $60 \mathrm{wt} . \mathrm{-} \%$ of the latter product corresponded to the formula shown in Figure 11(a), while the remaining 40 wt.- $\%$ was an open POSS having the structure of a resin (Figure 11(b)). All POSS molecules were used as received. $\varepsilon$-Caprolactam, kindly supplied by DSM Research, Geleen, The Nederlands, and $\varepsilon$-aminocaproic acid (ACA, from Fluka), were used as received.

The epoxy-POSS samples were used both in the melt mixing and in the in-situ polymerization approach.

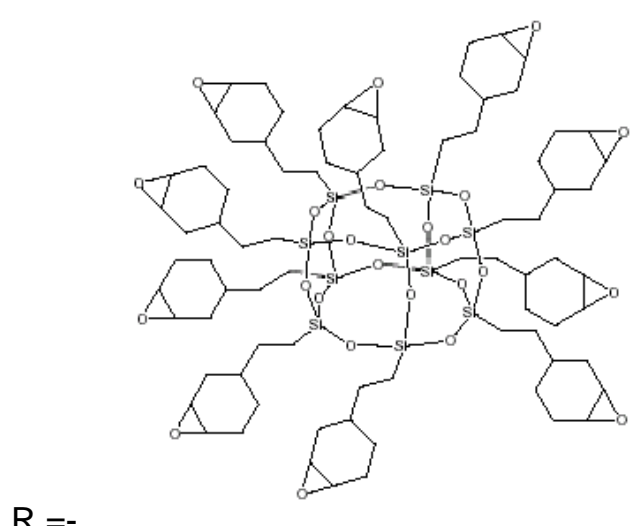

(a)

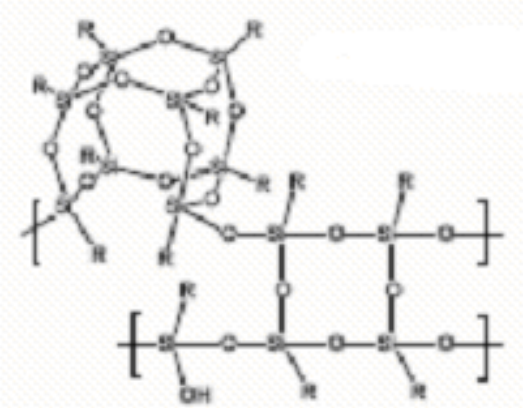

(b)

Fig. 11. Main structure of EPO408 (a) and of the resin present as an impurity in EPO408 (b). 


\section{Hybrid preparation in the microcompounder}

Pair system samples were prepared by melt compounding of the two components at $250{ }^{\circ} \mathrm{C}$ using a DSM MICRO15 intermeshing co-rotating and cone-shaped twin screw microcompounder, with a mixing compartment volume of approximately $15 \mathrm{ml}$. Both polyamide and POSS were added simultaneously. PA6 was previously dried in a vacuum oven for at least $24 \mathrm{~h}$ at $80^{\circ} \mathrm{C}$ to remove moisture, while POSS was used as received. Three series of samples containing the epoxy-POSS molecules were prepared at different rpm and contact times (see Tables 1-3).

\section{Hybrid preparation in the mixer}

TECHNYLS ${ }^{\circledR} 27$ and EPO402 POSS were mixed in a glass mixer equipped with a mechanical stirrer under nitrogen blanket at $250{ }^{\circ} \mathrm{C}$. Characteristics of the prepared samples are described in Table 4.

\section{Hybrid preparation by in-situ polymerization of $\varepsilon$-caprolactam}

Hydrolytic polyamide 6 samples were synthesized at the same high temperature (250 ${ }^{\circ} \mathrm{C}$ ) adopted for the melt mixing, using an aluminium block heated by electric resistors connected to a rheostat. Mixtures of $\mathrm{CL}$ and ACA were introduced into the glass polymerization vessel at room temperature and heated to the polymerization temperature by placing the vessel in the aluminium block; typical polymerization time was $4 \mathrm{~h}$. POSS was introduced either at the beginning of the synthesis, or after 1 and 2 h. of polymerization, respectively. After polymerization and cooling, all solid samples were broken in small pieces and unreacted $\varepsilon$-caprolactam, higher oligomers and other low molar mass species were removed by Soxhlet extraction with methanol for $48 \mathrm{~h}$. Then, unbonded POSS fractions, coming from EPO402 and EPO408 molecules, respectively, were extracted in Soxhlet with tetrahydrofuran or chloroform for $24 \mathrm{~h}$. Table 5 summarizes the experimental conditions used for the samples prepared by this method.

SEM micrographs of the samples AJ1 and AJ2, obtained by SE and BS emission, are shown in Figures 9 and 10, respectively. The two POSS/PA6 pairs were prepared by adding the mono- and multi-functional POSS, respectively, to the two polyamide growing chains (after $1 \mathrm{~h}$ from the start of $\mathrm{CL}$ polymerization).

\section{Characterization techniques}

Hybrid morphology was evaluated using a LEO scanning electron microscope Model Stereoscan 440 coupled to an EDS detector. Samples were prepared by freezing pieces in liquid nitrogen followed by high-speed impact to create fresh fracture surfaces. WAXD patterns were recorded using a Philips PW 1830 powder diffractometer (Ni-filtered $\mathrm{Cu}, \mathrm{K}_{\alpha}$ radiation). Solution viscosity of neat PA6 and of the various composites was measured in a suspended level Ubbelohde viscometer in 96 wt. $\% \mathrm{H}_{2} \mathrm{SO}_{4}\left(\right.$ at $20^{\circ} \mathrm{C}$ ) and in 2,2,2-trifluoroethanol (at $25^{\circ} \mathrm{C}$ ).

\section{Acknowledgements}

The precious help of Dr. Mauro Michetti for SEM measurements is gratefully acknowledged. The present study was supported in part by NoE "Nanofun Poly". The authors acknowledge also the support of NoE "Nanofun Poly" for the diffusion of the research results. 


\section{References}

[1] Schwab, J. J.; Lichtenhan, J. D. Appl. Organomet. Chem. 1998, 12, 707.

[2] Li, G.; Wang, L.; Ni, H.; Pittman, C. U. J. Inorg .Organomet. Polym. 2001, 11, 123.

[3] Joshi, M.; Butola, B. S.; J. Macromol. Sci., Polym. Rev. 2004, 44, 389 [and references quoted therein].

[4] Phillips, S. H.; Haddad, T.S.; Tomczac, S. J. Curr. Opin. Solid State Mater. Sci. 2004, 8, 21.

[5] Leu, C. M.; Chang, Y. T.; Wei, K. H. Macromolecules 2003, 36, 9122.

[6] Xu, H. Y.; Kuo, S. W.; Lee, J.S.; Chang, F.C. Macromolecules 2002, 35, 8788.

[7] Huang, J. C.; He, C.; Xiao, Y.; Mya, K. Y.; Dai, J.; Siow, Y. P. Polymer, 2003, 44, 4491.

[8] Chen, W. Y.; Wang, Y. Z.; Kuo, S. W.; Huang, C. F.; Tung, P. H.; Chang, F. C. Polymer, 2004, 45, 6897.

[9] Kim, G. M.; Qin H.; Fang, X.; Sun, F. C.; Mather, P. T. J. Polym. Sci., Part B: Polym. Phys. 2003, 41, 3299.

[10] Yei, D. R.; Kuo, S. W.; Su, Y. C.; Chang, F. C. Polymer, 2004, 45, 2633

[11] Pyun, J.; Matyjaszewski, K.; Wu, J.; Kim, G.; Chun, S. B.; Mather, P. T. Polymer 2003, 44, 2739.

[12] Zheng, L; Kasi, R. M.; Farris, R. J.; Coughlin, E.B. J. Polym. Sci., Part A: Polym. Chem. 2002, 40, 885.

[13] Lichtenhan, J. D. Mat. Res. Soc. Symp. Proc. 1996, 435, 3.

[14] Fina, A.; Abbenhuis, H. C. L.; Frache, A.; Tabuani, D.; Camino, G. Polym. Degrad. Stab. 2006, 91, 1064.

[15] Fina, A.; Abbenhuis, H. C. L.; Frache, A.; Tabuani, D.; Camino, G. Polym. Degrad. Stab. 2006, 91, 2275.

[16] Fina, A.; Tabuani, D.; Carniato, F.; Frache, A.; Boccaleri, E.; Camino, G. Thermochim. Acta, 2006, 440, 36.

[17] Schwab, J. J.; Lichtenhan, J. D.; Chaffee, K. P.; Gordon, J. C.; Otonari, Y. A.; Carr, M. J.; Bolf, A. J. Polym. Prepr. 1997, 38, 518.

[18] Böhning, M.; Hao, N.; Schönhals, A. Desalination 2006, 200, 142.

[19] Zheng, L.; Waddon, A. J.; Farris, R. J.; Coughlin, E. B. Macromolecules, 2002, 35, 2375.

[20] Li, G. Z.; Wang, L.; Toghiani, H.; Daulton, T. L.; Pittman, C. U. Polymer, 2002, $43,4167$.

[21] Waddon, A. J.; Zheng, L.; Farris, R. J.; Coughlin, E. B. Nano Lett. 2002, 2, 1149.

[22] Abad, M. J.; Barral, L.; Fasce, D. P.; Williams, R. J. J. Macromolecules 2003, 36, 3128.

[23] Matějka, L.; Strachota, A.; Pleštil, J.; Whelan, P.; Steinhart, M.; Šlouf, M. Macromolecules 2004, 37, 9449.

[24] Strachota, A.; Kroutilová, I.; Kokářová, J.; Matějka, L. Macromolecules 2004, 37, 9457.

[25] Yoon, K. H.; Polk, M. B.; Park, J. H.; Min, B. G.; Schiraldi, D. A. Polym. Int. 2005, $54,47$.

[26] Ma, J.; Li, Q. Advanced Materials Research, v 11-12, AICAM 2005 Proceedings of the Asian International Conference on Advanced Materials, 2006, $\mathrm{p}$ 323.

[27] Zhang, Y.; Lee, S.; Yoonessi, M.; Liang, K.; Pittman, C.U. Polymer 2006, 47, 2984.

[28] Lee, Y. J.; Kuo, S. W.; Huang, C. F.; Chang, F. C. Polymer 2006, 47, 4378. 
[29] Ueda, K.; Nakai, M.; Hattori, K.; Yamada, K.; Tai, K. Kobunshi Ronbunshu 1997, $56,401$.

[30] Lide, D. R. Handbook of Chemistry and Physics, Taylor \& Francis CRC Press, Boca Raton (FL) USA 1995. 